\title{
Wall reabsorption effects on heat and mass transfer of viscous fluid in a narrow leaky tube
}

\author{
Aamir Shahzad ${ }^{1}$. Waqar A. Khan ${ }^{2}$
}

Received: 3 September 2020 / Accepted: 22 December 2020 / Published online: 11 January 2021

(c) The Author(s) $2021 \quad$ OPEN

\begin{abstract}
The steady heat and mass transfer problem of flow of an incompressible Newtonian fluid is investigated in this study. The axisymmetric flow of a non-isothermal and highly viscous fluid is considered through a narrow leaky tube of uniform cross-section with linear reabsorption across the wall. The Navier-Stokes equations are solved for axially symmetric and slow flow in the tube. The effects of linear reabsorption parameter on the dimensionless radial and axial velocities, temperature, concentration, shear stress, leakage flux, fractional reabsorption, pressure drop across the tube as well as the Nusselt and Sherwood numbers have been investigated analytically. For $50 \%$ fractional reabsorption, inlet radial velocity is half of the reabsorption velocity along the tube. It has been shown that increase in the strength of linear reabsorption parameter considerably reduces the radial velocity, while, axial velocity shows opposite behaviour. At the exit region ( $z=0.9$ ), reverse flow phenomenon is observed for higher values of reabsorption parameter. The pressure, flow rate and wall shear stress decreases after entrance region $(z=0.1)$ of the tube. Nusselt number and Sherwood number show opposite behaviour inside the tube. At $z=0.1$ the magnitude of Nusselt number is maximum, while the Sherwood number is minimum at the exit region with higher value of reabsorption parameter.
\end{abstract}

Keywords Leaky tube · Incompressible flow · Reabsorption - Exact solutions · Leakage flux · Fractional reabsorption · Heat and mass transfer

$\begin{array}{ll}\text { List of symbols } \\ B_{r} \quad \text { Brinkman number } \\ C p & \text { Specific heat at constant pressure }(\mathrm{J} / \mathrm{kg} \mathrm{k}) \\ C_{1}, C_{2} & \text { Constants of integration } \\ D & \text { Coefficient of mass diffusivity }\left(\mathrm{m}^{2} / \mathrm{s}\right) \\ \Delta p & \text { Pressure drop } \\ L & \text { Length of the tube }(\mathrm{m}) \\ k & \text { Thermal conductivity coefficient }(\mathrm{W} / \mathrm{m} \mathrm{k}) \\ K_{T} & \text { Thermal-diffusion ratio } \\ p & \text { Pressure }(\mathrm{Pa}) \\ P r & \text { Prandtl number } \\ p_{0} & \text { Inlet fluid pressure }(\mathrm{Pa}) \\ P_{e} & \text { Peclet number } \\ q(z) & \text { Leakage flux }\left(\mathrm{m}^{2} / \mathrm{s}\right) \\ \dot{q} & \text { Heat transfer rate }\end{array}$

Re Reynolds number

$R \quad$ Radius of the tube $(\mathrm{m})$

$Q_{0} \quad$ Entrance flow rate $\left(\mathrm{m}^{3} / \mathrm{s}\right)$

$T \quad$ Temperature (k)

$u \quad$ Radial velocity $(\mathrm{m} / \mathrm{s})$

$U_{0} \quad$ Normalized inlet fluid velocity $(\mathrm{m} / \mathrm{s})$

$S_{c} \quad$ Schmidt number

$S_{r} \quad$ Soret number

$N_{u} \quad$ Nusselt number

$S_{h} \quad$ Sherwood number

$Q(z) \quad$ Normalized reduced flow rate

$w \quad$ Axial velocity $(\mathrm{m} / \mathrm{s})$

$\triangle$ Aamir Shahzad, aamir@cuiatd.edu.pk|'Department of Mathematics, COMSATS University Islamabad, Abbottabad Campus, Abbottabad, Pakistan. ${ }^{2}$ Department of Mechanical Engineering, College of Engineering, Prince Mohammad Bin Fahd University, Al Khobar 31952, Kingdom of Saudi Arabia. 


\section{Greek symbols}

$\alpha_{L} \quad$ Normalized reabsorption parameter

$\theta \quad$ Normalized temperature

$\phi \quad$ Normalized concentration

$\mu \quad$ Fluid viscosity $\left(\mathrm{N} \mathrm{s} / \mathrm{m}^{2}\right)$

$\delta \quad$ Ratio of length to height

$\tau_{w} \quad$ Normalized wall shear stress $(\mathrm{Pa})$

\section{Introduction}

The flow of viscous fluids in a leaky wall tube has several applications in medical and engineering sciences, for example, separation processes in multi-component mixtures, inflow in the nephron tubules, the flow of impure blood through a dialyzer (artificial kidney), reverse osmosis desalination, ultrafiltration, membrane separation, diffusion and more recently cross flow microfiltration. The application of Poiseuille's law is not appropriate due to fluid leakage at the walls to study the heat and mass transfer in such situations. Berman [1] presented the hydrodynamical study of flow in a permeable tube. He obtained the expressions for velocity and pressure with uniform seepage across the walls. His work was extended by Sellars [2], and obtained series solution for large Reynolds number. Later on, approximate solution of flow of laminar fluid flow in permeable channel with uniform suction/injection was obtained by Yuan [3], who investigated the flow in case of moderate to high suction or injection velocities across the walls. Terrill [4] have studied the flow through permeable channel with different permeability for small Reynolds number to get the velocity components and pressure drop. Macey [5] studied the flow and pressure in a permeable channel with variable reabsorption across the walls. Also, Macey [6] obtained the expressions for flow and pressure in a porous tube with decaying flow rate. Later, Kozinski et al. [7] extended the work of Macey's and presented exact solution for the flow of linear viscous fluid through a porous walled duct. Marshall et al. [8] considered the creeping flow of a Newtonian fluid through a rigid permeable tube and obtained closedform solutions for the pressure and velocity fields. They also obtained approximate solutions for the small seepage rates. Further, Radhakrishnamcharya et al. [9] also presented the solutions for creeping flow of Newtonian fluid in a permeable non uniform tube. Recently, Muthu et al. [10] studied the hydrodynamics of viscous fluid in a nonuniform porous channel using regular perturbation method. They found the velocity components at different locations inside the channel, also pressure drop along the channel/tube has been presented. Later, they also investigated the flow and pressure inside the porous tube with flow rate model [11]. Later, this work was extensively studied by Siddiqui et al. [12], they found the numeric values of reabsorption parameters for
$80 \%$ fractional reabsorption and showed that the study has relevance with flow of glomerular filtrate with in the kidney. Also, this work was extended by Haroon et al. [13] for periodic wall reabsorption. They found the expressions for velocity components, flow rate and pressure drop inside the porous channel. Farooq et al. [14] also extended the work of Muthu et al. [10] to slip flow condition considering Newtonian fluid flow inside the wavy channel.

In preceding studies, authors considered the hydrodynamics of viscous fluid flow in porous channels/tubes with application to flow in the kidney. But in general, heat and mass transfer mechanism has also several applications in biosciences and in industries, for example, the air movement in the pores of fibrous material due to heat convection, conduction in tissues and radiation between environment and its surface, food processing mass and diffusion in reverse osmosis. Terrill et al. [15] presented the analytical solution for heat and mass transfer of the two dimensional laminar and non-isothermal flow of linearly viscous fluid in a porous channel. Walker et al. [16] found the exact solution of the diffusion equation, while numerical solutions of the energy equation were discussed for small injection rates. Raithby [17] used the similarity solutions to evaluate the pressure gradient, Nusselt number, and Sherwood number in the two dimensional flow in a permeable channel. Ross [18] developed a mathematical model of mass transfer in a long permeable tube and demonstrated that the exit concentration decreases markedly as the diameter, membrane permeability and tube length increase. Sreedevi et al. [19] studied the impacts of the governing parameters on the heat and mass transfer of nanofluid flow over stretching surface with chemical reaction, suction, slip effects and thermal radiation.

In the literature presented above, this study is new in different aspects. First, there is a lack of information regarding the heat and mass transfer through a permeable tube with reabsorption across the walls. Secondly, the model presented by researcher is improved to heat and mass transfer in a permeable tube with linear reabsorption across the walls. Also, the components of velocity, pressure drop, wall shear stress, temperature profile and mass concentration distribution as well as the heat transfer coefficient (Nusselt number) and the mass transfer coefficient (Sherwood number) at the porous wall of the tube with linear wall reabsorption are also presented.

\section{Mathematical formulation of the problem}

Consider the flow of a steady, non-isothermal, laminar and incompressible Newtonian fluid in a permeable tube of radius $R$ and length $L$. A cylindrical coordinate system $(r, \theta, z)$ is chosen with the $z$-axis aligned with the midway 
and $r$ - axis being taken perpendicular to the walls of the tube, Fig. 1. At $z=0$ fluid enters the tube having axial flow rate $Q_{0}$, then some of the fluid at $r=R$ is filtered across the leaky walls of the tube and remaining $Q_{L}$ leaves at $z=L$. The wall of the tube is maintained at temperature $T_{0}$ and the average temperature of the fluid is assumed to be $T_{a}$. The tube is assumed long $(R \ll L)$ enough to neglect the end effects. The flow in this situation becomes two dimensional and the velocity profile is given by the following equation:

$\mathbf{V}=[u(r, z), 0, w(r, z)]$,

where $u$ and $w$ are the velocities in the radial and axial directions, respectively.

The equations governing the motion of an incompressible and non-isothermal Newtonian fluid through a tube are given by [18]:

$\frac{1}{r} \frac{\partial(r u)}{\partial r}+\frac{\partial w}{\partial z}=0$

$$
\begin{gathered}
\rho\left[u \frac{\partial u}{\partial r}+w \frac{\partial u}{\partial z}\right]=-\frac{\partial p}{\partial r}+\mu\left[\frac{\partial^{2} u}{\partial r^{2}}\right. \\
\left.+\frac{1}{r} \frac{\partial u}{\partial r}-\frac{u}{r^{2}}+\frac{\partial^{2} u}{\partial z^{2}}\right]
\end{gathered}
$$

$$
\rho\left[u \frac{\partial w}{\partial r}+w \frac{\partial w}{\partial z}\right]=-\frac{\partial p}{\partial z}+\mu\left[\frac{\partial^{2} w}{\partial r^{2}}+\frac{1}{r} \frac{\partial w}{\partial r}+\frac{\partial^{2} w}{\partial z^{2}}\right]
$$

$$
\begin{aligned}
\rho C_{p}\left[u \frac{\partial T}{\partial r}+w \frac{\partial T}{\partial z}\right]=k\left[\frac{\partial^{2} T}{\partial r^{2}}+\frac{1}{r} \frac{\partial T}{\partial r}+\frac{\partial^{2} T}{\partial z^{2}}\right] \\
+\mu\left[2\left\{\left(\frac{\partial u}{\partial r}\right)^{2}+\left(\frac{u}{r}\right)^{2}+\left(\frac{\partial w}{\partial r}\right)^{2}\right\}+\left(\frac{\partial u}{\partial z}+\frac{\partial w}{\partial r}\right)^{2}\right]
\end{aligned}
$$

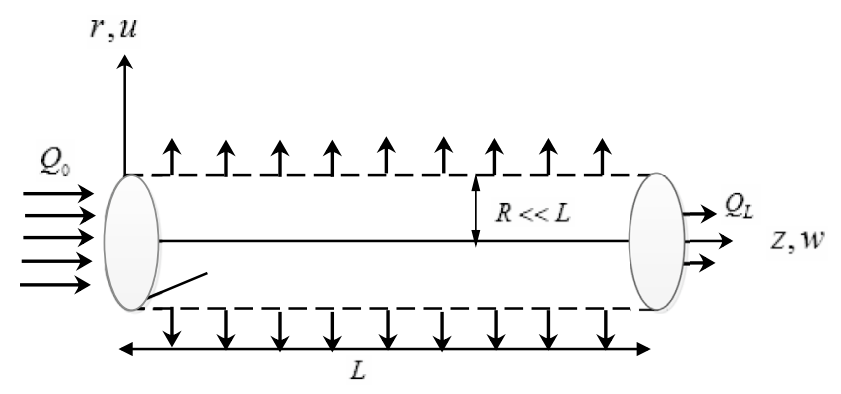

$$
\begin{gathered}
{\left[u \frac{\partial C}{\partial r}+w \frac{\partial C}{\partial z}\right]=D\left[\frac{\partial^{2} C}{\partial r^{2}}+\frac{1}{r} \frac{\partial C}{\partial r}+\frac{\partial^{2} C}{\partial z^{2}}\right]} \\
+\frac{D K_{T}}{T_{a}}\left[\frac{\partial^{2} T}{\partial r^{2}}+\frac{1}{r} \frac{\partial T}{\partial r}+\frac{\partial^{2} T}{\partial z^{2}}\right]
\end{gathered}
$$

where $p$ is the hydrodynamic pressure, $\rho$ is the density, $k$ is thermal conductivity, $C_{p}$ is the specific heat at constant pressure, $D$ is the coefficient of mass diffusivity, $K_{T}$ is the thermal-diffusion ratio, and $T_{a}$ is the mean temperature and $\mu$ is the viscosity of the fluid. The boundary conditions are taken as

$u(R, z)=V_{0}-\alpha_{L} z$

$w(R, z)=0$,

$T(R, z)=T_{0}$

$C(R, z)=C_{0}$

$u(0, z)=0$,

$\frac{\partial w(0, z)}{\partial r}=0$

$\frac{\partial T(0, z)}{\partial r}=0$,

$\frac{\partial C(0, z)}{\partial r}=0$,

$2 \pi \int_{0}^{R} r w(r, 0) d r=Q_{0}$

$p(r, 0)=p_{0}$

where $V_{0}$ is inlet upward velocity at $z=0$ and $\alpha_{L}$ is linear reabsorption velocity parameter along the tube.

Using the dimensionless quantities

Fig. 1 Geometry of the problem 


$$
\begin{aligned}
r^{*} & =\frac{r}{R^{\prime}} \quad z^{*}=\frac{z}{L^{\prime}}, \quad u^{*}=\frac{\pi R L u}{Q_{0}}, \quad w^{*}=\frac{\pi R^{2} w}{Q_{0}}, \\
p^{*} & =\frac{\pi R^{4} p}{\mu Q_{0} L} \\
\theta & =\frac{T-T_{0}}{T_{0}}, \quad P_{e}=\frac{\rho C_{p} Q_{0}}{\pi k R}, \quad B_{r}=\frac{\mu Q_{0}^{2}}{\pi^{2} k T_{0} R^{4}} \\
\delta & =\frac{R}{L^{\prime}} \\
R_{e} & =\frac{Q_{0}}{\pi v L^{\prime}} \quad \phi=\frac{C-C_{0}}{C_{0}}, \quad S_{c}=\frac{\mu}{\rho D}, \\
S_{r} & =\frac{\mu K_{T} T_{0}}{\rho D T_{m} C_{0}},
\end{aligned}
$$

where $P_{e}, B_{r}, R_{e}, S_{c}$ and $S_{r}$ are Peclet, Brinkman, Reynolds, Schmidt and Soret numbers. Equations (2-5), after removing * becomes

$$
\begin{aligned}
& \frac{1}{r} \frac{\partial(r u)}{\partial r}+\frac{\partial w}{\partial z}=0 \\
& R_{e} \delta^{2}\left[u \frac{\partial u}{\partial r}+w \frac{\partial u}{\partial z}\right] \\
& \quad=-\frac{\partial p}{\partial r}-\delta^{2}\left[\frac{\partial^{2} u}{\partial r^{2}}+\frac{1}{r} \frac{\partial u}{\partial r}-\frac{v}{r^{2}}+\delta^{2} \frac{\partial^{2} u}{\partial z^{2}}\right], \\
& R_{e}\left[u \frac{\partial w}{\partial r}+w \frac{\partial w}{\partial z}\right] \\
& \quad=-\frac{\partial p}{\partial z}+\frac{\partial^{2} w}{\partial r^{2}}+\frac{1}{r} \frac{\partial w}{\partial r}+\delta^{2} \frac{\partial^{2} w}{\partial z^{2}} .
\end{aligned}
$$$$
P_{e} \delta\left[u \frac{\partial \theta}{\partial r}+w \frac{\partial \theta}{\partial z}\right]
$$$$
=\left[\frac{\partial^{2} \theta}{\partial r^{2}}+\frac{1}{r} \frac{\partial \theta}{\partial r}+\delta^{2} \frac{\partial^{2} \theta}{\partial z^{2}}\right]
$$$$
+B_{r}\left[2 \delta^{2}\left\{\left(\frac{\partial u}{\partial r}\right)^{2}+\left(\frac{u}{r}\right)^{2}+\left(\frac{\partial w}{\partial r}\right)^{2}\right\}\right.
$$$$
\left.+\left(\delta^{2} \frac{\partial u}{\partial z}+\frac{\partial w}{\partial r}\right)^{2}\right]
$$

$$
\begin{aligned}
R_{e}\left[u \frac{\partial \phi}{\partial r}+w \frac{\partial \phi}{\partial z}\right] \\
=\frac{1}{S_{c}}\left[\frac{\partial^{2} \phi}{\partial r^{2}}+\frac{1}{r} \frac{\partial \phi}{\partial r}+\delta \frac{\partial^{2} \phi}{\partial z^{2}}\right] \\
\quad+S_{r}\left[\frac{\partial^{2} \theta}{\partial r^{2}}+\frac{1}{r} \frac{\partial \theta}{\partial r}+\delta^{2} \frac{\partial^{2} \theta}{\partial z^{2}}\right]
\end{aligned}
$$

$$
2 \int_{0}^{1} r w(r, 0) d r=1
$$

$p(r, 0)=P_{0}$,

where $U_{0}=\frac{\pi R L V_{0}}{Q_{0}}, \alpha=\frac{\pi R L^{2} \alpha_{L}}{Q_{0}}$ and $p_{0}=\frac{\pi R^{4} p_{0}}{\mu Q_{0} L}$ are inlet, linear reabsorption velocities and entrance pressure parameters. Equations (18-32) is the developed model capable of describing the heat and mass transfer of Newtonian fluid through a permeable tube with reabsorption across the walls. The solution of the model is explained in the next section.

\section{Solution of the problem}

For the solution of the problem, $\delta$ and $R_{e}$ are assumed small [20], the above equations can be written as

$\frac{\partial p}{\partial r}=0$,

$\frac{\partial p}{\partial z}-\frac{\partial^{2} w}{\partial r^{2}}-\frac{1}{r} \frac{\partial w}{\partial r}=0$

$\frac{\partial^{2} \theta}{\partial r^{2}}+\frac{1}{r} \frac{\partial \theta}{\partial r}+B_{r}\left(\frac{\partial w}{\partial r}\right)^{2}=0$,

$\frac{\partial^{2} \phi}{\partial r^{2}}+\frac{1}{r} \frac{\partial \phi}{\partial r}+S_{c} S_{r}\left(\frac{\partial^{2} \theta}{\partial r^{2}}+\frac{1}{r} \frac{\partial \theta}{\partial r}\right)=0$,

The boundary conditions in dimensionless form are

$u(1, z)=U_{0}-\alpha z$,

.


$w(r, z)=\frac{1}{4} \frac{d p}{d z}\left(r^{2}-1\right)$.

Substituting above Eq. (37) in Eq. (18), the expression for radial velocity with the help of boundary conditions (27) reduces to

$u(r, z)=\frac{1}{16} \frac{d^{2} p}{d z^{2}}\left(2 r-r^{3}\right)$

Equations (37-38) cannot describe the motion of the fluid particles inside the tube because of the unknown quantity $\frac{d p}{d z}$. To evaluate $\frac{d p}{d z}$, the boundary condition (23) is used, which transforms Eq. (38) into the the following differential equation in terms of pressure

$\frac{d^{2} p}{d z^{2}}=16\left(U_{0}-\alpha z\right)$

Integrating Eq. (39) twice, pressure becomes

$p(z)=-\frac{8}{3} \alpha z^{3}+8 U_{0} z^{2}+C_{1} z+C_{2}$.

After using condition (32) above equation reduces to

$p(z)=-\frac{8}{3} \alpha z^{3}+8 U_{0} z^{2}+C_{1} z+P_{0}$.

Now, $C_{1}$ is the only constant to determine. Combining Eqs. (42) and (37) in Eq. (31), the value of constant is

$C_{1}=-8$.

So, the final expression for pressure becomes

$p(z)=-\frac{8}{3} \alpha z^{3}+8 U_{0} z^{2}-8 z+p_{0}$

therefore, the expressions for velocity components are

$u(r, z)=-\frac{1}{2}\left(2 \alpha z-2 U_{0}\right)\left(2 r-r^{3}\right)$,

$w(r, z)=-2\left(\alpha z^{2}-2 U_{0} z+1\right)\left(r^{2}-1\right)$.

After using Eq. (45) in Eq. (35), the expression for temperature profile inside the permeable tube is obtained as

$\theta(r, z)=1-B_{r}\left(\alpha z^{2}-2 U_{0} z+1\right)^{2}\left(r^{4}-1\right)$.

Using Eq. (46) in Eq. (35), the resultant equation is solved with conditions (26) and (30) and expression for concentration profile inside the permeable tube becomes

$\phi(r, z)=1+S_{c} S_{r} B_{r}\left(\alpha z^{2}-2 U_{0} z+1\right)^{2}\left(r^{4}-1\right)$

which depends on $S_{c} S_{r}$ and $B_{r}$.

\subsection{Flow rate}

The flow rate inside the tube can be calculated by using the formula

$Q(z)=\frac{\pi \bar{Q}(z)}{Q_{0}}=2 \int_{0}^{1} r w(r, z) d r$,

where $\bar{Q}(z)$ is dimensional flow rate. Using Eq. (45) in Eq. (48), the flow rate becomes

$Q(z)=1+\alpha z^{2}-2 U_{0} z$.

From above equation flow behaviour in axial direction can be analyzed.

\subsection{Average pressure}

The average pressure inside the tube can be calculated by using the formula

$\overline{p(z)}=2 \int_{0}^{1} r p(z) d r=p(z)$,

The pressure drop inside the tube can now be calculated using the following formula

$\Delta p=\bar{p}(0)-\bar{p}(z)$,

using Eq. (43) in above formula, pressure drop takes the following form

$\Delta p=\frac{8}{3} \alpha z^{3}-8 U_{0} z^{2}+8 z$.

From Eq. (52), the amount of pressure that is permanently lost as the fluid passes inside tube can be observed.

\subsection{Wall shear stress}

The wall shear stress is calculated by

$$
\begin{aligned}
\tau_{w} & =-\left.\tau_{r z}\right|_{r=1} \\
& =-\left.\frac{\partial u}{\partial r}\right|_{r=1}
\end{aligned}
$$

Using Eq. (44) in above relation we find

$\tau_{w}=U_{0}-\alpha z$.

From Eq. (54), it is noted that wall shear stress decreases inside the tube. 


\subsection{Leakage flux}

The leakage at every location inside the tube is obtained as

$q(z)=\frac{d Q(z)}{d z}=2\left(U_{0}-\alpha z\right)$,

Above equation describes the quantity of fluid reabsorbed at any axial location inside the tube.

\subsection{Fractional reabsorption}

The amount of fluid filtered from the leaky walls is calculated by using the relation

$F R=\frac{Q(0)-Q(1)}{Q(0)}=2 U_{0}-\alpha$.

The fractional reabsorption is important quantity that describes the quantity of fluid reabsorbed across the tube walls. For $50 \%$ fractional reabsorption, inlet radial velocity is half of the reabsorption velocity along the tube. Also, amount of mass flow rate can also be studied from Eq. (56).

\subsection{Heat transfer}

Heat is transported mainly by conduction near the walls, so

$\ddot{q}=-k\left(\frac{1}{r} \frac{\partial(r T)}{\partial r}+\frac{\partial T}{\partial z}\right)_{r=H}$
$\dot{q}=-\left(\frac{1}{r} \frac{\partial(r \theta)}{\partial r}+\delta \frac{\partial \theta}{\partial z}\right)_{r=1}$,

where $\ddot{q}$ is dimensional heat transfer rate, while $\dot{q}=\frac{\ddot{q} R}{T_{0} k}$ is dimensionless heat transfer rate. Sine $\delta$ is small so, by using Eq. (46) in Eq. (57), the expression for heat transfer becomes

$\dot{q}=4\left(\alpha z^{2}-2 U_{0} z+1\right)^{2} B_{r}-1$.

\subsection{Nusselt number}

The Nusselt number may be obtained by a non dimensional analysis of Fourier's law since it is equal to the dimensionless temperature gradient of the form

$$
\begin{aligned}
N u & =\frac{\dot{q} L}{k\left(T-T_{0}\right)} \\
\frac{N u k T_{0}}{L} & =\frac{\dot{q}}{\theta},
\end{aligned}
$$

after using Eqs. (57) and (46), the expression for Nusselt number becomes

$$
N u=\frac{4\left(\alpha z^{2}-2 U_{0} z+1\right)^{2} B_{r}-1}{1-B_{r}\left(\alpha z^{2}-2 U_{0} z+1\right)^{2}\left(r^{4}-1\right)} .
$$

At the wall the above expression is same with Eq. (58).

\subsection{Mass transfer}

The mass transfer coefficient at the wall is defined as

$$
\begin{aligned}
J & =-D\left(\frac{1}{r} \frac{\partial(r \phi)}{\partial r}+\frac{\partial \phi}{\partial z}\right)_{r=R} \\
S_{h} & =\frac{J R}{C_{0} D}=-\left(\frac{1}{r} \frac{\partial(r \phi)}{\partial r}+\delta \frac{\partial \phi}{\partial z}\right)_{r=1}
\end{aligned}
$$

where $J$ is dimensional mass transfer rate, while $S_{h}=\frac{J R}{C_{0} D}$ is a Sherwood number (dimensionless mass transfer rate). Since, $\delta$ is small so, by using Eq. (47) in Eq. (61), above equation becomes

$S_{h}=-1-4 S_{c} S_{r} B_{r}\left(\alpha z^{2}-2 U_{0} z+1\right)^{2}$,

which is strongly dependent on the involved parameters.

\section{Results and discussion}

The current research has been carried out to study the wall reabsorption effect on heat and mass transfer of non isothermal viscous fluid in a permeable tube. The mathematical model is exactly solved for the dimensionless radial and axial velocities $(u(r, z) / w(r, z))$, temperature $(\theta(r, z))$ and concentration $(\phi(r, z))$. For the validation of the results, it is pointed out here that all the mathematical results given in Eqs. (33-36) along with boundary conditions (23-32) are satisfied.

The influence of linear reabsorption parameter $\alpha$ on $u(r, z) / w(r, z), \theta(r, z), \phi(r, z)$, flow rate $Q(z)$, pressure drop $\Delta p(z)$, wall shear stress $\tau_{w}$, Nusselt number Nu and Sherwood number $S_{h}$ are illustrated in Figs. $2,3,4,5,6,7,8,9$ and 10. In Figs. 2 and 3, the impact of $\alpha$ on the dimensionless radial and axial velocities at different locations, such as, entrance $(z=0.1)$, middle position $(z=0.5)$ and exit region ( $z=0.9$ ) is shown, respectively. It is perceived that the $u(r, z)$ is higher at $(z=0.1)$ as compared to $(z=0.5)$ and $(z=0.9)$ due to fluid leakage across the walls of the tube. Also, the magnitude of $u(r, z)$ reduces along the tube with an increase in $\alpha$, while, opposite behavior is observed for the $w(r, z)$ at the same locations, see Fig. 3) At $z=0.5$, the velocity $w(r, z)$ profile is found to be higher as compared to other location. At $z=0.9$, reverse flow phenomenon is 


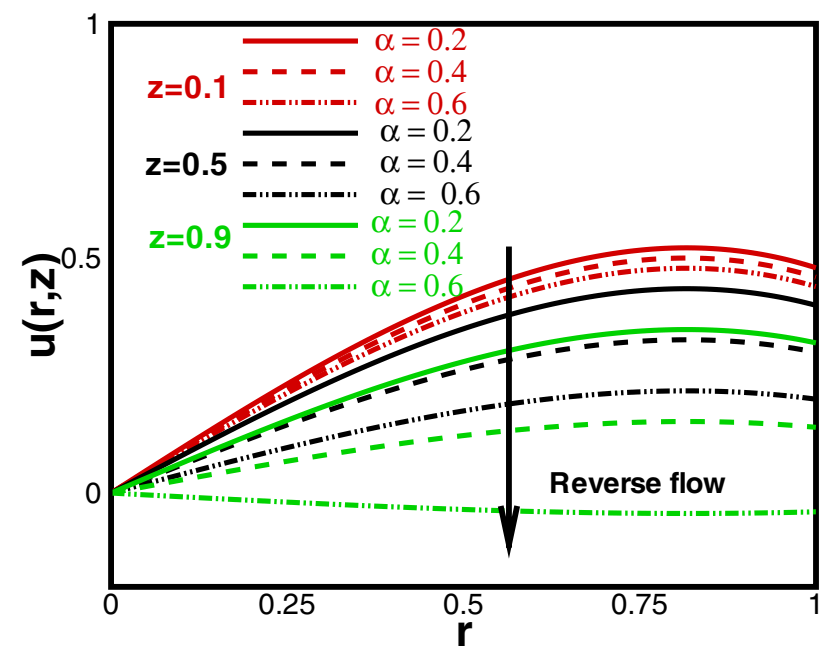

Fig. 2 Effect of $\alpha$ on radial velocity at at different location $(z=0.1,0.5,0.9)$, when $U_{0}=0.5$

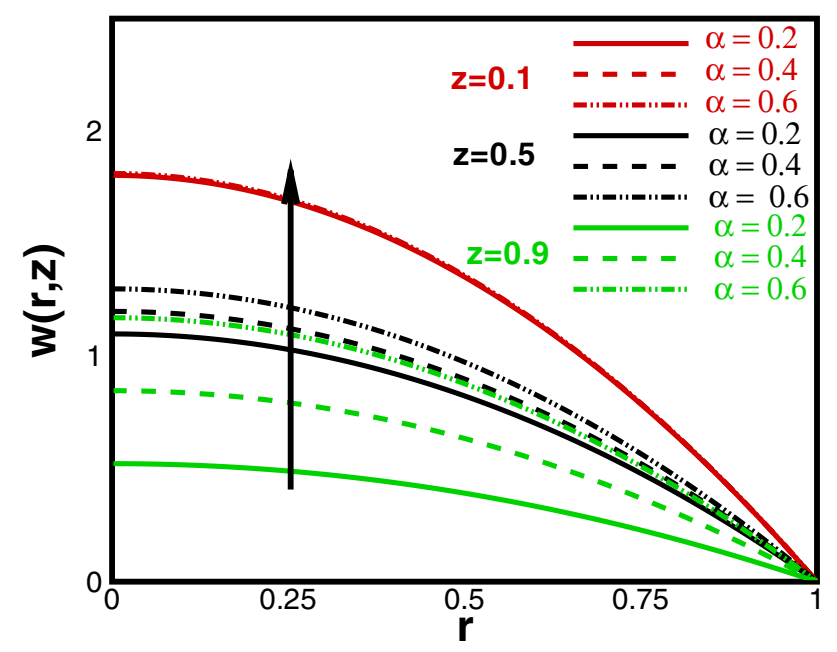

Fig. 3 Effect of $\alpha$ on axial velocity at at different location $(z=0.1,0.5,0.9)$, when $U_{0}=0.5$

observed that indicates the leakage of the fluid across the walls before reaching the end region. Also,it is observed that near the centerline of the tube, flow is maximum due to pressure gradient and near the walls the fluid flow become stationary due to wall friction and fluid viscosity.

The effect of $\alpha$ on flow rate, $Q(z)$ is observed in Fig. 4, which decreases from entrance region to exit region. Also with increasing $\alpha$, the profile of $Q(z)$ increases and maximum magnitude is noticed at the exit of the tube. For the high value of $\alpha$, the fluid inside the tube reduces that confirms high flow rate near the exit region. The pressure inside the tube also decays from entrance region to the exit region and shows opposite behaviour as compared to flow rate. With increasing the strength of $\alpha$, pressure

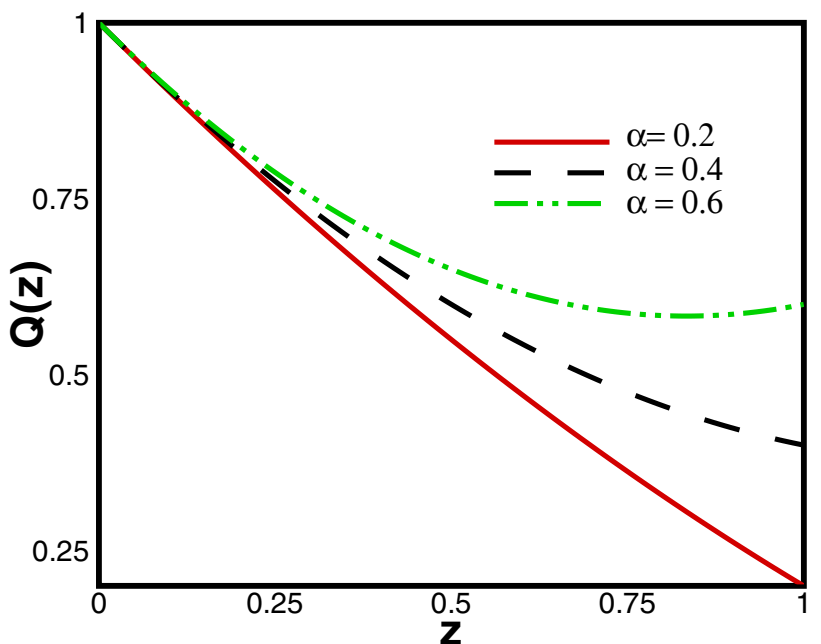

Fig. 4 Effect of $\alpha$ on flow rate along the tube, when $U_{0}=0.5$

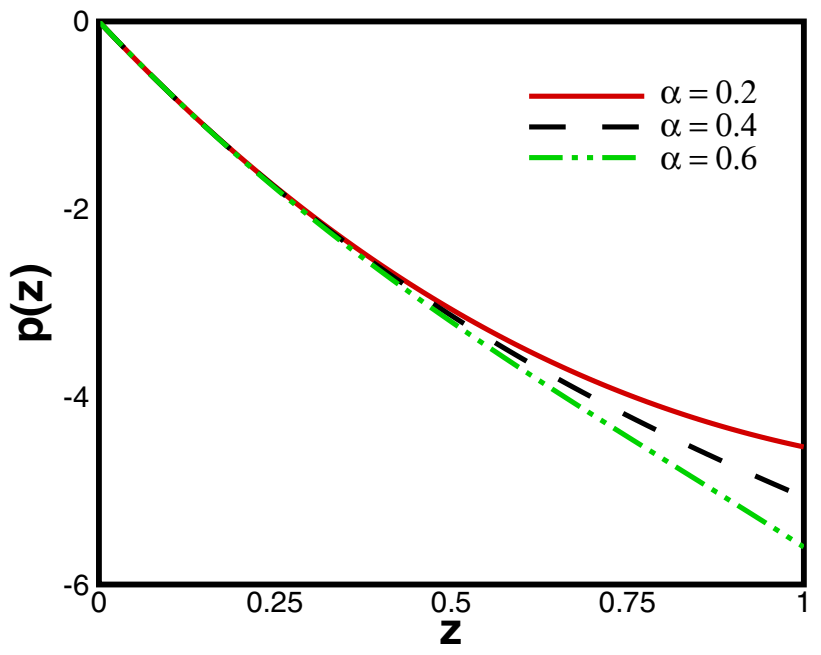

Fig. 5 Effect of $\alpha$ on pressure along the tube, when $U_{0}=0.5$

reduces near the exit region. The shear stress at the wall $\tau_{w}$ has same nature as pressure inside the tube, see Figs. 4 and 5 .

The influence of $\alpha$ on the dimensionless $\theta(r, z)$ at different locations are explained in Fig. 6. The effects of $\alpha$ on the dimensionless $\theta(r, z)$ are found to be highest at the center and then reduces to minimum at the wall surface. At the entrance region $\theta(r, z)$ is found to be higher than middle and exit region of the tube. As $\alpha$ increases, the dimensionless $\theta(r, z)$ increases at each axial location.

The variation of dimensionless $\phi(r, z)$ in radial direction with $\alpha$ can be visualized in Fig. 8 for $U_{0}=0.5$ at different locations inside the tube. It is inferred that the dimensionless concentration at the entrance is lower than middle and exit region of the tube. Also it 


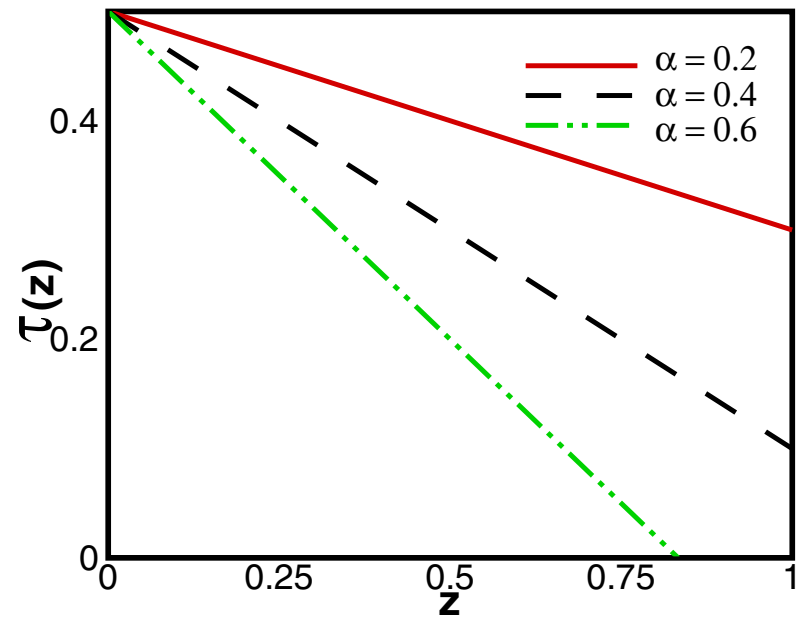

Fig. 6 Effect of $\alpha$ on wall shear stress along the tube, when $U_{0}=0.5$

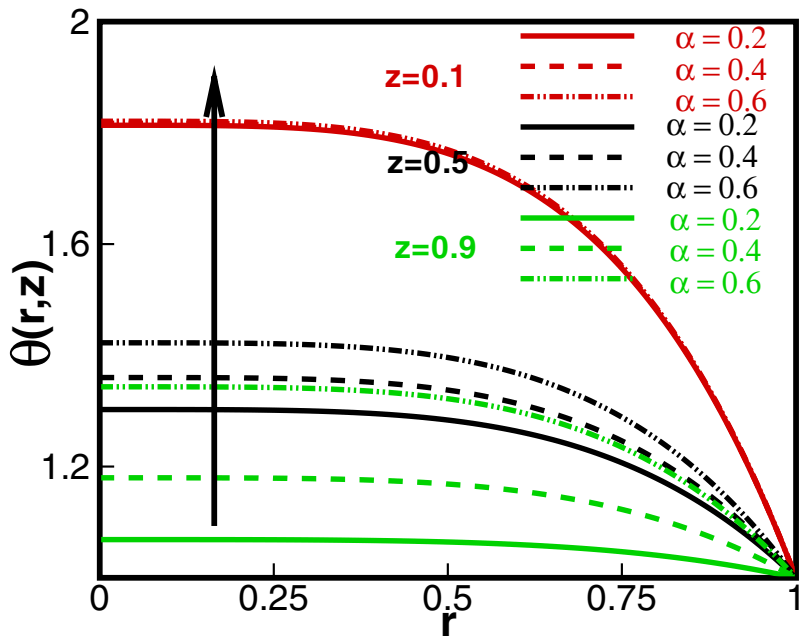

Fig. 7 Effect of $\alpha$ on temperature at different location $(z=0.1,0.5,0.9)$, when $U_{0}=0.5, B_{r}=1$

increases from center of the tube to the surface of the tube for inlet velocity $U_{0}=0.5$. In fact, higher values of $\alpha$ reduces the dimensionless $\phi(r, z)$ in radial direction. When $\alpha$ increases, the dimensionless $\phi(r, z)$ decreases in the axial direction.

The variation of $\mathrm{Nu}$ in axial direction with $\alpha$ is illustrated in Fig. 9. For same inlet velocity, there is a maximum $\mathrm{Nu}$ at the entrance region that decreases in the axial direction. Also $\alpha$ enhances the $\mathrm{Nu}$ in the exit region. Figure 10 displays the variation of $S_{h}$ in axial direction with $\alpha$, for the same inlet velocities. In Fig. 10, it is noticed that $S_{h}$ is found to be lower at the exit region and then increases in the axial direction with an increase in the $\alpha$. At the exit region, $S_{h}$ is maximum for lower value of $\alpha$.

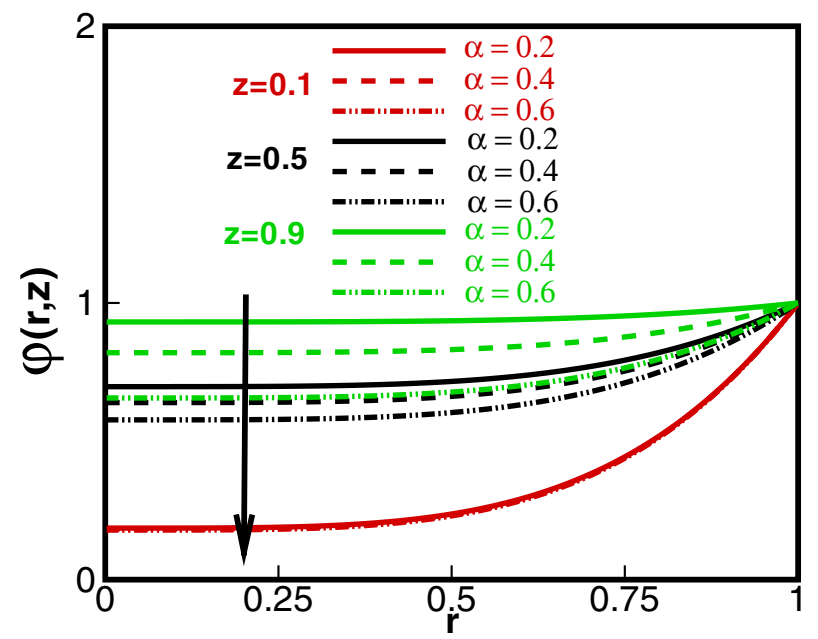

Fig. 8 Effect of $\alpha$ on concentration at different location $(z=0.1,0.5,0.9)$, when $U_{0}=0.5, B_{r}=1, S_{c}=1, S_{r}=1$

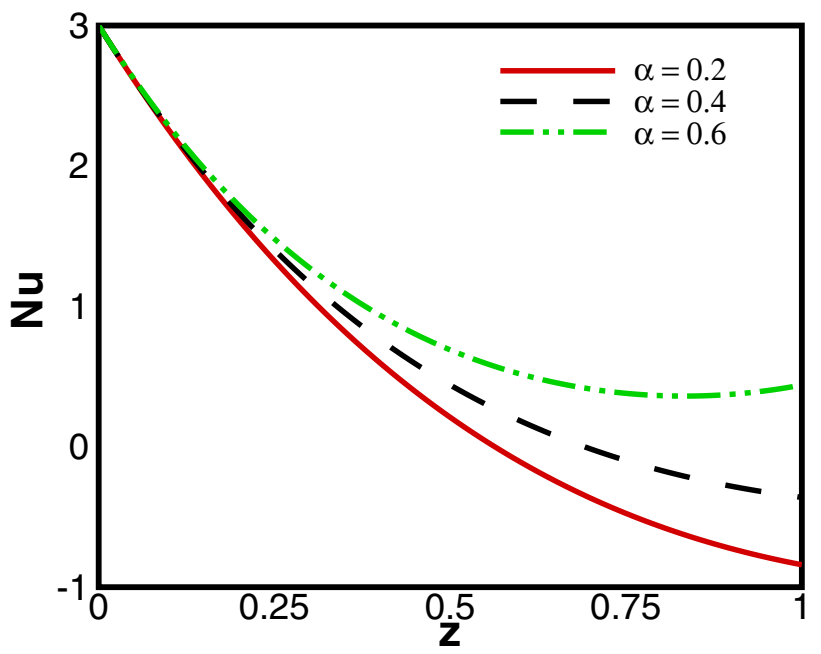

Fig. 9 Effect of $\alpha$ on Nusselt number inside the tube, when $U_{0}=0.5, B_{r}=1$

\section{Concluding remarks}

The steady flow of a non-isothermal, laminar and incompressible Newtonian fluid is considered in a leaky tube with linear reabsorption across the walls. From this study, the following conclusions can be drawn.

1. Radial velocity component is higher in entrance region as compared to the middle position and the exit region of the tube.

2. Reverse flow phenomenon is noticed for axial velocity at the exit region of the tube. 




Fig. 10 Effect of $\alpha$ on Sherwood number inside the tube, when $U_{0}=0.5, B_{r}=1$

3. For $50 \%$ fractional reabsorption, inlet radial velocity is half of the reabsorption velocity along the tube.

4. With increasing the strength of linear reabsorption parameter radial velocity decreases while axial velocity increases at different locations inside the tube.

5. Temperature field increases at the centerline of the tube with decreasing linear reabsorption parameter.

6. With increasing linear reabsorption parameter, concentration decreases from center to the surface for same inlet velocity while increases for higher inlet velocity.

7. Flow rate, pressure and wall shear stress decreases along the tube.

8. With increasing linear reabsorption pressure decreases while flow rate and wall shear stress increases along the tube.

9. Nusselt number at the wall decreases along the tube its magnitude is maximum at the exit region of the tube with increases linear reabsorption parameter.

10. Sherwood number increases along the tube and with increasing linear reabsorption parameter its profile decreases near the exit region of the tube.

\section{Compliance with ethical standards}

Conflict of interest The authors declare that they have no conflict of interest.

Open Access This article is licensed under a Creative Commons Attribution 4.0 International License, which permits use, sharing, adaptation, distribution and reproduction in any medium or format, as long as you give appropriate credit to the original author(s) and the source, provide a link to the Creative Commons licence, and indicate if changes were made. The images or other third party material in this article are included in the article's Creative Commons licence, unless indicated otherwise in a credit line to the material. If material is not included in the article's Creative Commons licence and your intended use is not permitted by statutory regulation or exceeds the permitted use, you will need to obtain permission directly from the copyright holder. To view a copy of this licence, visit http://creativecommons .org/licenses/by/4.0/.

\section{References}

1. Berman AS (1958) Laminar flow in an annulus with porous walls. J Appl Phys 29(1):71-75

2. Sellars JR (1955) Laminar flow in channels with porous walls at high suction Reynolds numbers. J Appl Phys 26(4):489-490

3. Yuan SW (1956) Further investigation of laminar flow in channels with porous walls. J Appl Phys 27(3):267-269

4. Terrill RM (1964) Laminar flow in a uniformly porous channel (Laminar flow in two-dimensional channel with porous walls assuming uniformly injected fluid). Aero-naut Q 15:299-310

5. Macey RI (1963) Pressure flow patterns in a cylinder with reabsorbing walls. Bull Math Biophys 25(1):1-9

6. Macey RI (1965) Hydrodynamics in the renal tubule. Bull Math Biophys 27(2):117-124

7. Kozinski AA, Schmidt FP, Lightfoot EN (1970) Velocity profiles in porous-walled ducts. Ind Eng Chem Fundam 9(3):502-505

8. Marshall EA, Trowbridge EA (1974) Flow of a Newtonian fluid through a permeable tube: the application to the proximal renal tubule. Bull Math Biol 36(5-6):457-476

9. Radhakrishnamacharya G, Chandra P, Kaimal MR (1981) A hydrodynamical study of the flow in renal tubules. Bull Math Biol 43(2):151-163

10. Muthu P, Berhane T (2010) Mathematical model of flow in renal tubules. Int J Appl Math Mech 6(20):94-107

11. Muthu $P$, Berhane T (2010) Fluid flow in a rigid wavy non-uniform tube: application to flow in renal tubules. ARPN J Eng Appl Sci 5:15-19

12. Siddiqui AM, Haroon T, Shahzad A (2016) Hydrodynamics of viscous fluid through porous slit with linear absorption. Appl Math Mech-Engl Ed 37:361

13. Haroon T, Siddiqui AM, Shahzad A (2016) Stokes flow through a slit with periodic reabsorption: an application to renal tubule. Alexandr Eng J 55(2):1799-1810

14. Farooq J, Mushtaq M, Munir S, Ramzan M, Chung JD, Farooq $\mathrm{U}$ (2018) Slip flow through a non-uniform channel under the influence of transverse magnetic field. Sci Rep 8(1):1-14

15. Terrill RM, Walker G (1968) Heat and mass transfer in laminar flow between parallel porous plates. Appl Sci Res 18(1):193-220

16. Walker G, Terrill RM (1974) Mass transfer cooling of laminar flow between parallel porous plates. J Heat Transf 96(3):343-347

17. Raithby GD (1972) Heat transfer in tubes and ducts with wall mass transfer. Can J Chem Eng 50(4):456-461

18. Ross SM (1974) A mathematical model of mass transport in a long permeable tube with radial convection. J Fluid Mech 63(01):157-175

19. Sreedevi P, Reddy PS, Chamkha A (2020) Heat and mass transfer analysis of unsteady hybrid nanofluid flow over a stretching sheet with thermal radiation. SN Appl Sci 2(7):1-15

20. Happel J, Brenner H (1965) Low Reynolds number hydrodynamics with special applications to particulate media. Prentice-Hall, Prentice

Publisher's Note Springer Nature remains neutral with regard to jurisdictional claims in published maps and institutional affiliations. 